\title{
Activation Mechanism of Protein Kinase B by DNA-dependent Protein Kinase Involved in the DNA Repair System
}

\author{
Yuwen Li ${ }^{1 \#}$, Longzhen Piao"\#, Keum-Jin Yang', Sanghee Shin ${ }^{1}$, Eulsoon Shin ${ }^{1}$, Kyung Ah Park', \\ Hee Sun Byun ${ }^{1}$, Minho Won ${ }^{1}$, Byung Lyul Choi ${ }^{1}$, Hyunji Lee ${ }^{1}$, Young-Rae Kim ${ }^{1}$, Jang Hee Hong ${ }^{1}$, \\ Gang Min Hur ${ }^{1}$, Jeong-Lan Kim², Jae Youl Cho ${ }^{3}$, Jeong Ho Seok ${ }^{1 *}$ and Jongsun Park ${ }^{1 *}$ \\ ${ }^{1}$ Department of Pharmacology, Cell Signaling Laboratory, Research Center for Transgenic Cloned Pigs, \\ Daejeon Regional Cancer Center, Cancer Research Institute, Research Institute for Medical Sciences, Department of \\ ${ }^{2}$ Psychiatry, College of Medicine, Chungnam National University, Taejeon 301-131 \\ ${ }^{3}$ School of Bioscience and Biotechnology, and Institute of Bioscience and Biotechnology, \\ Kangwon National University, Chuncheon 200-701, Korea
}

(Received June 10, 2008; Revised August 8, 2008; Accepted August 11, 2008)

\begin{abstract}
DNA-dependent protein kinase (DNA-PK) is involved in joining DNA double-strand breaks induced by ionizing radiation or $\mathrm{V}(\mathrm{D}) \mathrm{J}$ recombination and is activated by DNA ends and composed of a DNA binding subunit, $\mathrm{Ku}$, and a catalytic subunit, DNA-PKcs. It has been suggested that DNA-PK might be $2^{\text {nd }}$ upstream kinase for protein kinase $B(P K B)$. In this report, we showed that Ser473 phosphorylation in the hydrophobic-motif of PKB is blocked in DNA-PK knockout mouse embryonic fibroblast cells (MEFs) following insulin stimulation, while there is no effect on Ser473 phosphorylation in DNA-PK wild type MEF cells. The observation is further confirmed in human glioblastoma cells expressing a mutant form of DNA-PK (M059J) and a wild-type of DNA-PK (M059K), indicating that DNA-PK is indeed important for PKB activation. Furthermore, the treatment of cells with doxorubicin, DNA-damage inducing agent, leads to PKB phosphorylation on Ser473 in control MEF cells while there is no response in DNA-PK knockout MEF cells. Together, these results proposed that DNA-PK has a potential role in insulin signaling as well as DNA-repair signaling pathway.
\end{abstract}

Key words: DNA-PK, DNA damage, Protein kinase B, Insulin signaling, Cell Signaling

\section{INTRODUCTION}

Over time, DNA accumulates changes that activate proto-oncogenes and inactivate tumor-suppressor genes. The genetic instability driving tumorigenesis is fuelled by DNA damage and by errors made by the DNA machinery. However, 'spontaneous' mutations are insufficient to explain the lifetime cancer risk (Loeb, 1991). Indeed, numerous links have been identified between oncogenesis and acquired or inherited faulty genome guardians that cause a 'mutator' phenotype, highlighting the key role of DNA protection systems in tumor prevention (Hoeijmakers, 2001b). To prevent or counteract the time-dependent erosion of our genes

Correspondence to: Jongsun Park or Jeong Ho Seok, Department of Pharmacology, College of Medicine, Chungnam National University, Taejeon 301-131, Korea

E-mail: insulin@cnu.ac.kr or E-mail: jhseok@cnu.ac.kr

"These authors contributed equally to this work. due to undesired but irresistible accumulation of DNA injury one of the most important systems is DNA repair. Because there are so many different types of damage, it is simply impossible that one mechanism is able to cope with all of them. So, every repair system has its own tasks, its own spectrum of damage that it can recognize and fix and other repair systems will deal with other types of damage. But, as a whole, a network of repair systems will be able to cope with almost every possible lesion in the DNA (Citterio et al., 2000).

DNA double-strand breaks (DSBs) can be accidentally introduced in cells by the action of ionizing radiation or certain reactive radicals. These agents have the ability to initiate a series of chemical reactions that ultimately sever the DNA backbone, resulting in chromosome breakage and fragmentation of genes (Hoeijmakers, 2001). Because such corruption of genetic material inevitably leads to problems with replication and cell division, it is of the utmost importance that cells have a mechanism to counteract DSBs (van Gent et 
al., 2001). In addition, DSBs are generated in developing $B$ and $T$ cells during normal $V(D) J$ recombination, implying that a working DSB repair system is not only necessary for an effective defense against DNA-modifying agents but also for a functional immune system in higher organisms (Weterings and van Gent, 2004). As a result, two highly efficient DSB repair pathways have evolved in eukaryotic cells: homologous recombination (HR) and nonhomologous end joining (NHEJ) (Weterings and Chen, 2007). The core protein of the DNA-PK multi-protein complex is represented by a $\mathrm{Mr} \sim 460,000$ catalytic subunit (DNA-PKcs) which, in itself, is a serinethreonine kinase similar to proteins of the PI3K family (Hartley et al., 1995; Meek et al., 2004).

The serine/threonine kinase PKB (protein kinase B, also called Akt) constitutes an important node in diverse signaling cascades and acts as a major signal transducer downstream of activated PI3K (phosphoinositide 3-kinase) (Dummler and Hemmings, 2007). Mammalian cells contain three genes that encode three closely related and highly conserved isoforms of PKB, termed PKBolAkt1, PKB $/ / A k t 2$, and PKB $\gamma / A k t 3$ (Yang et al., 2004). Stimulation by numerous growth factors, cytokines, hormones and neurotransmitters can activate PKB/Akt in a phosphoinositide 3-kinase-dependent manner (Brazil et al., 2004). Through receptor tyrosine kinases, these stimuli cause phosphoinositide 3-kinase activation, and generation of the membrane phospholipid Ptdlns(3,4,5)P3. Ptdlns(3,4,5)P3 then recruits PKB/ Akt to the membrane, where it becomes phosphorylated at Thr308 and Ser473 (for PKBa/Akt1) by two upstream kinases, phosphoinositide-dependent kinase 1 and a yet to be identified Ser473 kinase. The unphosphorylated form of PKB is virtually inactive, and PDK1 phosphorylation stimulates its activity by at least 100 fold (Alessi et al., 1996, 1997; Stephens et al., 1998; Stokoe et al., 1997). Furthermore, there is a second regulatory site, Ser473 at the carboxyl terminus, termed the hydrophobic motif which is responsible for further 7- to 10-fold full-activation of PKB (Alessi et al., 1996). Recently, it has been shown that DNA-dependent protein kinase (DNA-PK) is a long sought after kinase, responsible for the Ser473 phosphorylation step in the activation of PKB (Feng et al., 2004).

In the current report, we further provided the evidence that DNA-PK is a Ser473 kinase responsible for PKB activation by using DNA-PK knockout MEF cells.

\section{MATERIALS AND METHODS}

Reagents and antibodies. Anti-PKB antibody (Ab10) has been described previously (Andjelkovic et al., 1997). Anti-phospho specific Thr308 or Ser473 (PKB) antibodies are from Cell Signaling. Anti-DNAPKcs (G4) antibody is obtained from Santa Cruz Biotech. Double-stranded fetal calf thymus DNA was from Sigma. The purified DNA-PKcs, Ku70/80 and DNA-PK substrate peptide were purchased from Promega. Inositol hexakisphosphate, Spermine, poly-L-lysine, Heparine, and poly (Glu-Na, Tyr) 4:1 were purchased from Sigma.

Cell culture and stimulation. M059J and M059K were from ATCC. DNA-PK wild type mouse embryonic fibroblast cells (MEFs), DNA-PK knockout MEFs, M059K cells, M059J cells, ataxia telangiectasia mutated (ATM) wild type MEFs and ATM knockout MEFs were maintained in DMEM supplemented with 10\% FCS, 1 mM nonessential amino acid (Gibco) and $20 \mathrm{mM}$ L-Glutamine (Gibco). And cells were serum-starved for $24 \mathrm{~h}$ before stimulation with $100 \mathrm{nM}$ insulin (Boehringer Mannheim) or $5 \mu \mathrm{M}$ doxorubicin (Sigma) for the indicated times.

In vitro kinase assays. In vitro DNA-PK assays were performed for $15 \mathrm{~min}$ at $30^{\circ} \mathrm{C}$. Briefly, $1.25 \mu \mathrm{g} / \mathrm{ml}$ of DNA-PKcs was assayed with or without $100 \mu \mathrm{g} / \mathrm{ml}$ of DNA and $1.75 \mu \mathrm{g} / \mathrm{ml}$ of $\mathrm{Ku}$ subunits, $1.0 \mathrm{mg} / \mathrm{ml}$ substrate peptide, $1 \mu \mathrm{M}$ protein kinase $\mathrm{A}$ inhibitor peptide (PKl; Bachem), and $50 \mu \mathrm{M}\left[\gamma_{-}{ }^{32} \mathrm{P}\right] A T P$ (Amersham; 1,000 2,000 cpm/pmol) in Z'0.05 buffer (25 mM HEPES $\mathrm{pH} 7.5,50 \mathrm{mM} \mathrm{KCl}, 10 \mathrm{mM} \mathrm{MgCl}, 20 \%$ glycerol, $1 \% \mathrm{w} /$ $\mathrm{v}$ Nonidet P-40 and $1 \mathrm{mM}$ dithiothreitol) (Beamish et al., 2000) as indicated in each experiment. All reactions were stopped by adding $50 \mu \mathrm{M}$ EDTA and processed as described previously (Park et al., 2001). Protein concentrations were determined by the method of Bradford (Bradford, 1976) using BSA as a standard.

Immunoblot analysis. Cell extracts were resolved by $6 \%$ or $12 \%$ SDS/PAGE and transferred to Immobilon $\mathrm{P}$ membranes (Millipore). The membranes were blocked for $30 \mathrm{~min}$ in $1 \times$ PBS containing $5 \%$ skimmed milk, and $0.1 \%$ Triton $\mathrm{X}-100$, followed by $2 \mathrm{~h}$ incubation with the first antibody diluted 1000-fold in the same blocking solution. The secondary antibody was a goat anti-rabbit or anti-mouse IgG HRP-conjugated antibody (Amersham Biosciences) diluted 2500-fold in the blocking buffer. The detection and quantitation of protein expression were developed by using the ECL development reagents (Pharmacia) and exposure to film.

Data analysis. The results from western blot analysis are a representative of three independent experiments. Kinase activity is the average $( \pm S D)$ of three independent experiments. 


\section{RESULTS}

The absence of Ser473 PKB kinase activity from DNA-PK knockout MEF cells. It has been suggested that DNA-PK act as an upstream kinase for PKB through Ser473 phosphorylation (Feng et al., 2004). Numerous studies have proposed that DNA-PK is involved in DNA-repair as well as V(D)J recombination (Hoeijmakers, 2001a). During last decade, several substrates for DNA-PK have been suggested in vitro as well as in vivo (Burma and Chen, 2004; Meek et al., 2004). However, the significance of those substrates is not well established. During the purification of Ser473 kinase from the membrane fraction of HEK 293 cells, in which the mechanism of PKB activation is well established (Andjelkovic et al., 1997, 1999), it has been found that DNA-PK as a Ser473 kinase (Feng et al., 2004). Therefore, we monitored the status of Ser473 phosphorylation of PKB in DNA-PK knockout MEFs (Taccioli et al., 1998) following the treatment of cells with insulin. As shown in Fig. 1, DNA-PK knock-out MEFs didn't properly respond to insulin stimulation in Ser473 phosphorylation of PKB whereas DNA-PK wild type control MEFs show a nice increase in Ser473 phosphorylation in a time-dependent manner. Thus these results indicate that DNA-PK is essential for PKB phosphorylation on Ser 473 and activation.

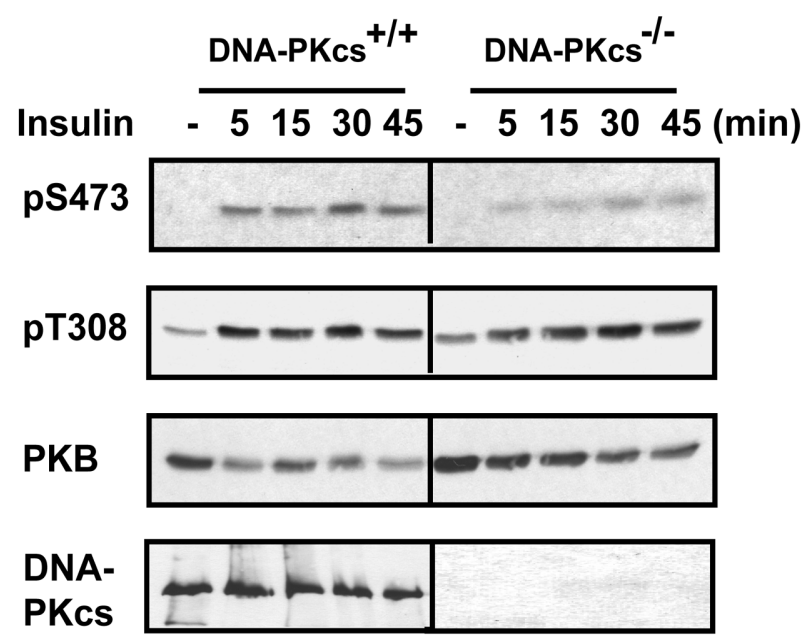

Fig. 1. The status of PKB activation in DNA-PK knockout mouse embryonic fibroblast (MEF) cells. DNA-PKcs wild type $(+/+)$ and knockout (-/-) MEFs were treated with $100 \mathrm{nM}$ insulin in the indicated time after 18 hour serumstarvation. Then $50 \mu \mathrm{g}$ of cell lysate were subjected to $6 \%$ or $12 \%$ SDS-PAGE and immunoblotted with pS473 or pT308 phospho-specific antibodies, anti-PKB antibodies or anti-DNA-PK antibodies. Each result is a representative of three independent experiments.
Lack of detection in Ser473 phosphorylation of PKB in human glioblastoma cells expressing an inactive mutant form of DNA-PK, M059J cells. In order to further develop the previous finding that DNAPK is responsible for Ser473 phosphorylation, we take the advantage of human glioblastoma cells expressing an inactive mutant form of DNA-PK (M059J) or an active wild type of DNA-PK (M059K) (Allalunis-Turner et al., 1993). As expected, Ser473 phosphorylation of PKB was impaired in M059J cells, but not in wild type control cells, M059K cells (Fig. 2), confirming that Ser473 phosphorylation of PKB is mediated by DNA-PK.

PKB activation is normal in ATM knockout MEF cells as well as ATM wild type MEF cells. Recently, Viniegra and colleagues provide new clues in the search of the unknown Ser473 kinase that full activation of PKB/Akt in response to insulin or ionizing radiation is mediated through ATM (Viniegra et al., 2005). Therefore we also monitored the status of Ser473 phosphorylation of PKB in ATM knockout MEFs together with ATM wild type MEFs. Contrast with the previous results, PKB activation in response to insulin treatment was increased in ATM knockout MEFs as well as ATM wild type control MEFs (Fig. 3).

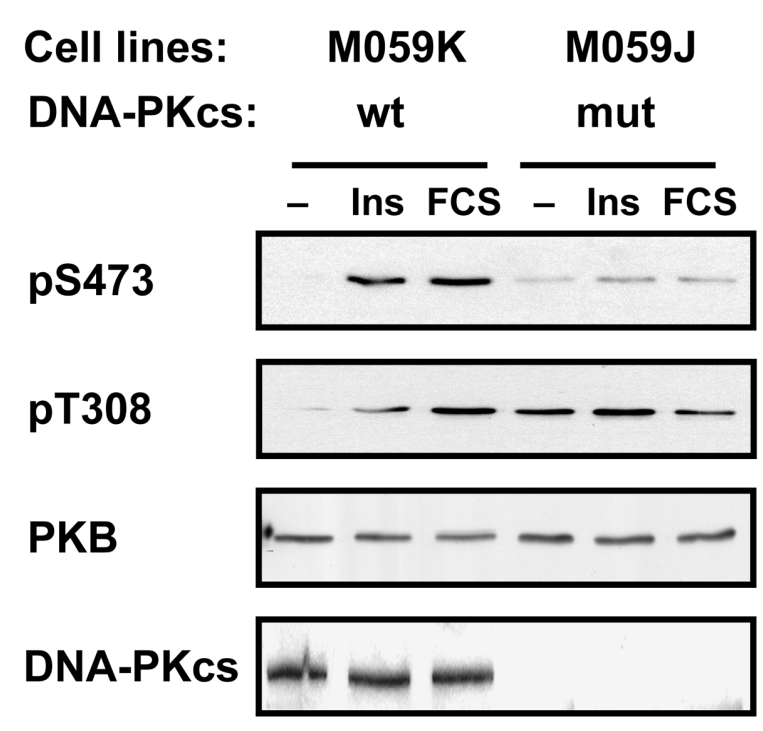

Fig. 2. Inhibition of insulin-mediated PKB activation in DNAPK-deficient human glioblastoma cell lines. Human glioblastoma cells expressing a wild type DNA-PK, M059K or an inactive form of DNA-PK, M059J cells were treated with $100 \mathrm{nM}$ insulin in the indicated time after 18 hour serumstarvation. Then $50 \mu \mathrm{g}$ of cell lysate were subjected to $6 \%$ or $12 \%$ SDS-PAGE and immunoblotted with pS473 or pT308 phospho-specific antibodies, anti-PKB antibodies or anti-DNA-PK antibodies. Each result is a representative of three independent experiments. 


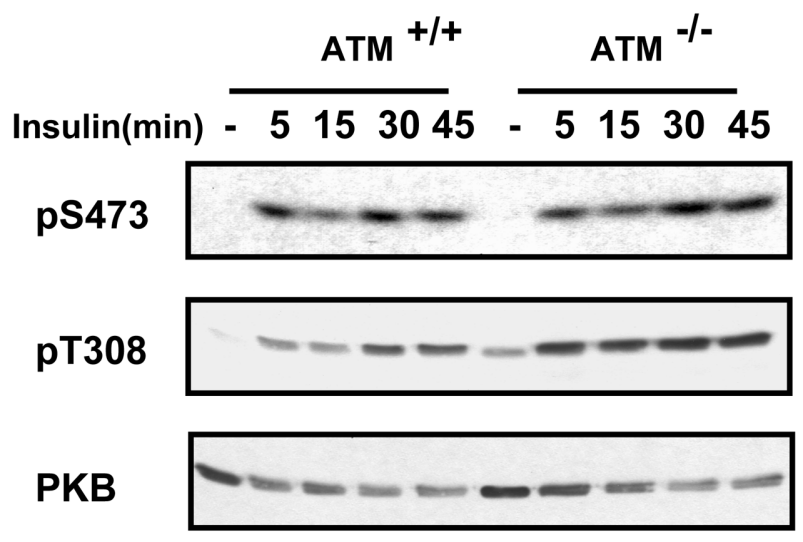

Fig. 3. Insulin-induced PKB activation in ATM knockout MEF cells. ATM wild type (+/+) and knockout (-/-) MEFs were treated with $100 \mathrm{nM}$ insulin in the indicated time and then analyzed by immunoblot analysis. Each result is a representative of three independent experiments.

Doxorubicin, a DNA-damage inducing agent, mediated Ser473 phosphorylation of PKB is inhibited in DNA-PK knockout MEF cells. Since DNA-PK play a major role in DNA-repairing system (Meek et al., 2004), we further examined the effects of doxorubicin, DNA-damage inducing agent, on Ser473 phosphorylation of PKB. Consistent with previous reports (Li et al., 2005; Quevedo et al., 2007), Ser473 phosphorylation of PKB is diminished in DNA-PK knockout MEFs whereas there is a gradual increase in Ser473 phosphorylation in a time-dependent manner in DNA-PK wild type control MEFs (Fig. 4A). This effect was not observed in ATM knockout MEFs (Fig. 4B), indicating that PKB activation by DNA-PK could also occur in DNA-damage condition.

Inositol hexakisphosphate do not activate DNAPK in presence of Ku70/Ku86. To further evaluate the effect of DNA-PK on PKB activation, we have screened the potential activator of DNA-PK. Inositol hexakisphosphate (IP6) has been found as a novel factor that is bound by DNA-PK and stimulates DNA endjoining in vitro (Byrum et al., 2004; Hanakahi et al., 2000; Hanakahi and West, 2002; Ma and Lieber, 2002). Therefore, we use IP6 for modulating DNA-PK activity in vitro in presence/absence of Ku70/Ku86 subunit. As shown in Fig. 5A, double-strand (ds) DNA is nicely able to induce the DNA-PK activity toward FSYtide whereas different concentration of IP6 failed to activate DNA-PK. Additionally, we also tested some of charged molecule which mimic the negative charge of dsDNA to activate DNA-PK activity such as Spermine, Poly-L-lysine, PolyGlu-Tyr, and Heparin. However, none of them success to activate DNA-PK activity toward FSYtide in presence of Ku70/Ku86 (Fig. 5B). Taken together, we were not able to find the modulator of DNA-PK activity addition to dsDNA.

Differential regulation of DNA-PK activity by $\mathrm{Mg}^{2+}$ and $\mathrm{Mn}^{2+}$. It has been reported that DNA-PK activity toward degenerative non-SQ peptide library can be increased in presence of $\mathrm{Mn}^{2+}$ instead of $\mathrm{Mg}^{2+}$ in in-vitro kinase assay (O'Neill et al., 2000). In addition, Chan et al found that DNA-PK activity is independent on doublestrand (ds) DNA ends and Ku70/80 subunit in presence of $\mathrm{Mn}^{2+}$ whereas DNA-PK activity is dependent on dsDNA ends and Ku70/80 subunit in presence of $\mathrm{Mg}^{2+}$ (Chan et al., 2000), suggesting the possibility of differential regulation of DNA-PK activity by $\mathrm{Mg}^{2+}$ and $\mathrm{Mn}^{2+}$. Therefore we test the DNA-PK activity toward FSYtide or p53tide with either $\mathrm{Mg}^{2+}$ or $\mathrm{Mn}^{2+}$ in in-vitro kinase reaction. Apparently, DNA-PK activity was not changed so much in these conditions (data not shown).

\section{DISCUSSION}

In higher eukaryotes, non-homologous end-joining
A

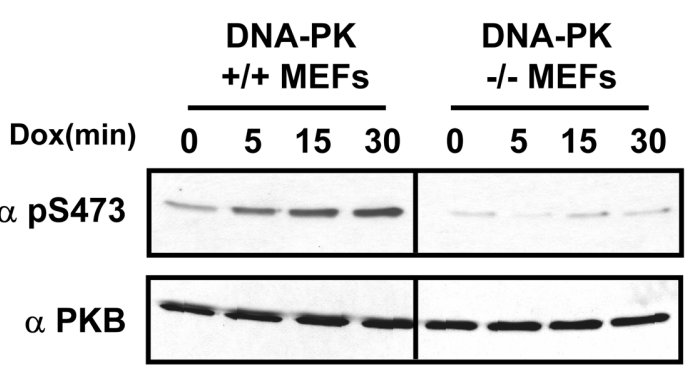

B

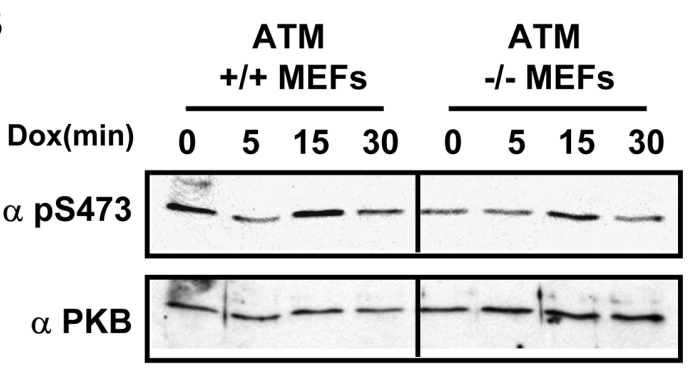

Fig. 4. The effects of Doxorubicin, DNA-damage inducing agent, on PKB activity in DNA-PK knockout MEF cells and ATM knockout MEF cells. (A) DNA-PK wild type (+/+), knockout $(-/-)$ MEFs, (B) ATM wild type (+/+) and knockout $(-/-)$ MEFs were treated with $30 \mu \mathrm{M}$ Doxorubicin in the indicated time after 18 hour serum-starvation. Then $50 \mu \mathrm{g}$ of cell lysate were subjected to $6 \%$ or $12 \%$ SDS-PAGE and immunoblotted with pS473 phospho-specific antibodies or anti-PKB antibodies. Each result is a representative of three independent experiments. 
A

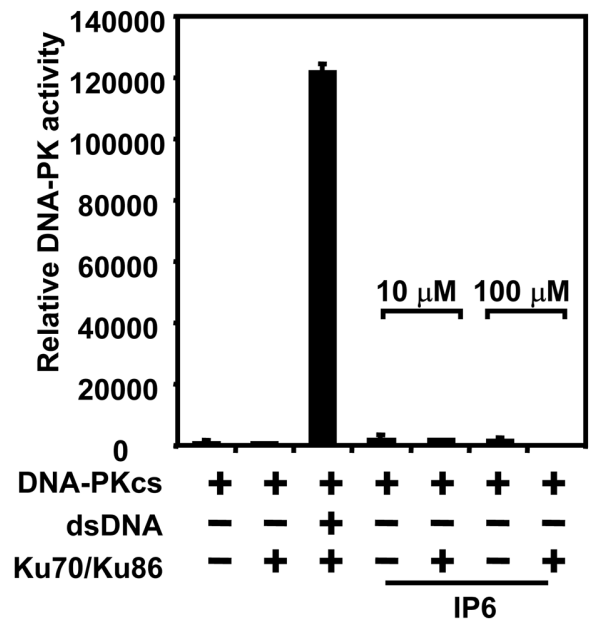

B

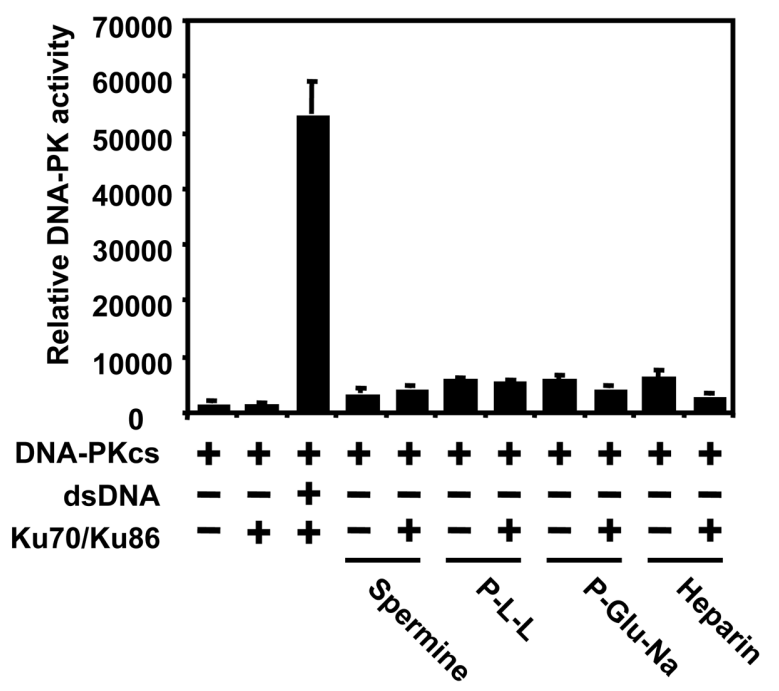

Fig. 5. The effects of InsP6 and polyions on DNA-PK activity toward FSYtide in vitro. (A) DNA-PK activity was assayed using FSYtide peptide as substrate with (+) or without (-) Ku subunit in the presence of different concentration of IP6 as indicated. (B) DNA-PK activity was assayed with (+) or without (-) Ku subunit in the presence of $0.2 \mathrm{mg} / \mathrm{ml}$ Spermine (Sper), poly-L-lysine (PLL), poly (Glu-Na, Tyr) 4:1 (P-Glu-Na) and Heparine (Hep). Activity of DNA-PK Kinase activity is the average ( \pm SD) of three independent experiments.

(NHEJ) DNA is the primary pathway that repairs these breaks. NHEJ also functions in developing lymphocytes to repair strand breaks that occur during $V(D) J$ recombination, the site-specific recombination process that provides for the assembly of functional antigenreceptor genes (Meek et al., 2004). In the last decade, an intensive research effort has focused on NHEJ resulting in a reasonable understanding of how doublestrand breaks are resolved. Six distinct gene products have been identified that function in this pathway (Ku70, Ku86, XRCC4, DNA ligase IV, Artemis, and DNAPKcs). Three of these comprise one complex, the DNAdependent protein kinase (DNA-PK). This protein complex is central during NHEJ, because DNA-PK initially recognizes and binds to the damaged DNA and then targets the other repair activities to the site of DNA damage (Weterings and Chen, 2007). A large body of evidence suggested that activation of PI3K/PKB pathway is associated with resistance to radiation in many cell lines (Gottschalk et al., 2005; Grana et al., 2002; Gupta et al., 2001, 2003; Li et al., 2004). Therefore, it is tempting to speculate that radiation-induced DNA damage will result in activating PI3K/PKB signaling pathway through DNA-PK, ATM and ATR.

In current report, we have clearly demonstrated that DNA-PK is a key regulator to control PKB activation in insulin and DNA-repair signaling. Immunoblot analysis of DNA-PK knockout MEF cells suggested that PKB phosphorylation on Ser473 is significantly inhibited in
DNA-PK knockout MEF cells following the treatment of cells with insulin (Fig. 1). These finding was further supported by the observation that PKB activation is blocked in human glioblastoma cells expressing an inactive mutant form of DNA-PK, M059J cells while PKB activation is normal in control M059K cells (Fig. 2). In addition, the treatment of cells with doxorubicin, a DNAdamage inducing agent, increased Ser473 phosphorylation of PKB in DNA-PK wild type MEFs, but not in DNA-PK knockout MEFs (Fig. 4A), suggesting that DNA-PK play a new role in PKB signaling.

Our results from ATM (-/-) MEFs (Fig. 3) contrast with the observation of Viniegra et al., who claimed that ATM is a major determinant of full PKB/Akt activation in response to insulin or gamma-radiation (Viniegra et al., 2005). However, ATM knockout MEFs in this report was generated from mice of p53 knockout background. Therefore, this discrepancy of observation is due to the fact that p53 somehow play a role in Ser473 phosphorylation of PKB in ATM knockout MEFs through DNA$P K$ in insulin signaling as well as DNA-repair signaling (Fig. 3 and 4B). Additionally, it has been proposed that mammalian target of rapamycin (mTOR) and its associated protein rictor are involved in Ser473 phosphorylation of PKB in Drosophila and human cells (Hresko and Mueckler, 2005; Sarbassov et al., 2005). Recently, Caporali and colleagues also provided the evidence of a novel function of ATR as an upstream activator of PKB in response to DNA damage induced by $0^{6}$-guanine 
methylating agents (Caporali et al., 2008).

Toker and colleagues suggested that phosphorylation of the hydrophobic motif on PKB requires catalytically competent PKB (Toker and Newton, 2000). To evaluate the possibility of PKB autophosphorylation on Ser473, we performed the in-vitro DNA-PK kinase assay with mono-phosphorylated PKB in presence of $1 \mu \mathrm{M}$ staurosporine (in which PKB activity is completely blocked while Ser473 kinase activity is resistant (Hill et al., 2001)). PKB autophosphorylation on Ser473 is not occurred even though PKB get phosphorylate on The308, which imply the active PKB (data not shown). In presence of $1 \mu \mathrm{M}$ staurosporine where PKB activity is completely inhibited (Hill et al., 2001), DNA-PK still phosphorylates PKB on Ser473 (data not shown). These results perfectly match with the previous report (Hill et al., 2001), indicating that DNA-PK is the Ser473 kinase for PKB.

In the current study, we further provided the evidence that DNA-PK is a responsible Ser473 kinase for PKB by using DNA-PK knockout MEF cells. We show that Ser473 phosphorylation of PKB is impaired in DNA-PK knockout MEF cells following insulin stimulation. Furthermore, similar observation was also obtained from DNA-PK deficient cells while there is no significant effect on Ser473 phosphorylation of PKB in ATM knockout MEF cells, which is another PI3K-like kinase. The treatment of cell with Doxorubicin, DNA-damage reagent, also lead to an increase in Ser473 phosphorylation in DNA-PK wild type MEF cells, which is blocked in DNAPK knockout MEF cells. Taken together, these data clearly demonstrate that DNA-PK has a novel role in PKB signaling in insulin and DNA-repair signaling pathway. Furthermore, this report supports the role of DNAPK in Ser473 phosphorylation for regulating PI3K/PKB signaling pathways. And it would provide better information for the clinical utilization of DNA-PK inhibitors.

\section{ACKNOWLEDGMENTS}

We would like to thank Dr. P.A. Jeggo (University of Sussex, UK) for DNA-PK knockout MEFs and Dr. F. W. Alt (Harvard University, USA) for ATM knockout MEFs. This work was supported by the ERC Program (R112002-100-02006-0) and the Basic Research Program (R01-2005-000-10240-0, F01-2005-000-10011-0) of the Korea Science \& Engineering Foundation grant funded by the Korea government (MOST), by a grant from the National R\&D Program for Cancer Control Ministry of Health \& Welfare, Republic of Korea. (NO-0720560) and by Research fund of Chungnam National University Hospital in 2006.

\section{REFERENCES}

Alessi, D.R., Andjelkovic, M., Caudwell, B., Cron, P., Morrice, N., Cohen, P. and Hemmings, B.A. (1996). Mechanism of activation of protein kinase B by insulin and IGF-1. Embo. J., 15, 6541-6551.

Alessi, D.R., James, S.R., Downes, C.P., Holmes, A.B., Gaffney, P.R., Reese, C.B. and Cohen, P. (1997). Characterization of a 3-phosphoinositide-dependent protein kinase which phosphorylates and activates protein kinase Balpha. Curr. Biol., 7, 261-269.

Allalunis-Turner, M.J., Barron, G.M., Day, R.S., 3rd, Dobler, K.D. and Mirzayans, R. (1993). Isolation of two cell lines from a human malignant glioma specimen differing in sensitivity to radiation and chemotherapeutic drugs. Radiat. Res., 134, 349-354.

Andjelkovic, M., Alessi, D.R., Meier, R., Fernandez, A., Lamb, N.J., Frech, M., Cron, P., Cohen, P., Lucocq, J.M. and Hemmings, B.A. (1997). Role of translocation in the activation and function of protein kinase B. J. Biol. Chem., 272, 31515-31524

Andjelkovic, M., Maira, S.M., Cron, P., Parker, P.J. and Hemmings, B.A. (1999). Domain swapping used to investigate the mechanism of protein kinase $B$ regulation by 3phosphoinositide-dependent protein kinase 1 and Ser473 kinase. Mol. Cell. Biol., 19, 5061-5072.

Beamish, H.J., Jessberger, R., Riballo, E., Priestley, A., Blunt, T., Kysela, B. and Jeggo, P.A. (2000). The C-terminal conserved domain of DNA-PKcs, missing in the SCID mouse, is required for kinase activity. Nucleic. Acids. Res., 28, 1506-1513.

Bradford, M.M. (1976). A rapid and sensitive method for the quantitation of microgram quantities of protein utilizing the principle of protein-dye binding. Anal. Biochem., 72, 248254.

Brazil, D.P., Yang, Z.-Z. and Hemmings, B.A. (2004). Advances in protein kinase $B$ signalling: AKTion on multiple fronts. Trends in Biochemical Sciences, 29, 233-242.

Burma, S. and Chen, D.J. (2004). Role of DNA-PK in the cellular response to DNA double-strand breaks. DNA Repair (Amst), 3, 909-918.

Byrum, J., Jordan, S., Safrany, S.T. and Rodgers, W. (2004). Visualization of inositol phosphate-dependent mobility of $\mathrm{Ku}$ : depletion of the DNA-PK cofactor InsP6 inhibits $\mathrm{Ku}$ mobility. Nucleic. Acids. Res., 32, 2776-2784.

Caporali, S., Levati, L., Starace, G., Ragone, G., Bonmassar, E., Alvino, E. and D'Atri, S. (2008). AKT is activated in an ATR-dependent manner in response to temozolomide and confers protection against drug-induced cell growth inhibition. Mol. Pharmacol., 74, 173-183.

Chan, D.W., Son, S.C., Block, W., Ye, R., Khanna, K.K., Wold, M.S., Douglas, P., Goodarzi, A.A., Pelley, J., Taya, Y., Lavin, M.F. and Lees-Miller, S.P. (2000). Purification and characterization of ATM from human placenta. A manganese-dependent, wortmannin-sensitive serine/threonine protein kinase. J. Biol. Chem., 275, 7803-7810.

Citterio, E., Vermeulen, W. and Hoeijmakers, J.H. (2000). Transcriptional healing. Cell., 101, 447-450. 
Dummler, B. and Hemmings, B.A. (2007). Physiological roles of PKB/Akt isoforms in development and disease. Biochem. Soc. Trans, 35, 231-235.

Feng, J., Park, J., Cron, P., Hess, D. and Hemmings, B.A. (2004). Identification of a PKB/Akt hydrophobic motif ser473 kinase as DNA-dependent protein kinase. J. Biol. Chem., 279, 41189-41196.

Gottschalk, A.R., Doan, A., Nakamura, J.L., Stokoe, D. and Haas-Kogan, D.A. (2005). Inhibition of phosphatidylinositol3-kinase causes increased sensitivity to radiation through a PKB-dependent mechanism. Int. J. Radiat. Oncol. Biol. Phys., 63, 1221-1227.

Grana, T.M., Rusyn, E.V., Zhou, H., Sartor, C.I. and Cox, A.D. (2002). Ras mediates radioresistance through both phosphatidylinositol 3-kinase-dependent and Raf-dependent but mitogen-activated protein kinase/extracellular signalregulated kinase kinase-independent signaling pathways. Cancer. Res., 62, 4142-4150.

Gupta, A.K., Bakanauskas, V.J., Cerniglia, G.J., Cheng, Y., Bernhard, E.J., Muschel, R.J. and McKenna, W.G. (2001). The Ras radiation resistance pathway. Cancer. Res., 61, 4278-4282.

Gupta, A.K., Cerniglia, G.J., Mick, R., Ahmed, M.S., Bakanauskas, V.J., Muschel, R.J. and McKenna, W.G. (2003). Radiation sensitization of human cancer cells in vivo by inhibiting the activity of PI3K using LY294002. Int. J. Radiat. Oncol. Biol. Phys., 56, 846-853.

Hanakahi, L.A., Bartlet-Jones, M., Chappell, C., Pappin, D. and West, S.C. (2000). Binding of inositol phosphate to DNA-PK and stimulation of double-strand break repair. Cell., 102, 721-729.

Hanakahi, L.A. and West, S.C. (2002). Specific interaction of IP6 with human Ku70/80, the DNA-binding subunit of DNA-PK. Embo. J., 21, 2038-2044.

Hartley, K.O., Gell, D., Smith, G.C., Zhang, H., Divecha, N., Connelly, M.A., Admon, A., Lees-Miller, S.P., Anderson, C.W. and Jackson, S.P. (1995). DNA-dependent protein kinase catalytic subunit: a relative of phosphatidylinositol 3-kinase and the ataxia telangiectasia gene product. Cell., 82, 849-856.

Hill, M.M., Andjelkovic, M., Brazil, D.P., Ferrari, S., Fabbro, D. and Hemmings, B.A. (2001). Insulin-stimulated protein kinase B phosphorylation on Ser-473 is independent of its activity and occurs through a staurosporine-insensitive kinase. J. Biol. Chem., 276, 25643-25646.

Hoeijmakers, J.H. (2001a). DNA repair mechanisms. Maturitas, 38, 17-22; discussion 22-13.

Hoeijmakers, J.H. (2001b). Genome maintenance mechanisms for preventing cancer. Nature, 411, 366-374.

Hresko, R.C. and Mueckler, M. (2005). mTOR.RICTOR is the Ser473 kinase for Akt/protein kinase B in 3T3-L1 adipocytes. J. Biol. Chem., 280, 40406-40416.

Li, B., Yuan, M., Kim, I.A., Chang, C.M., Bernhard, E.J. and Shu, H.K. (2004). Mutant epidermal growth factor receptor displays increased signaling through the phosphatidylinositol-3 kinase/AKT pathway and promotes radioresistance in cells of astrocytic origin. Oncogene, 23, 4594-4602.

Li, X., Lu, Y., Liang, K., Liu, B. and Fan, Z. (2005). Differen- tial responses to doxorubicin-induced phosphorylation and activation of Akt in human breast cancer cells. Breast. Cancer. Res., 7, R589-597.

Loeb, L.A. (1991). Mutator phenotype may be required for multistage carcinogenesis. Cancer. Res., 51, 30753079.

Ma, Y. and Lieber, M.R. (2002). Binding of inositol hexakisphosphate (IP6) to Ku but not to DNA-PKcs. J. Biol. Chem., 277, 10756-10759.

Meek, K., Gupta, S., Ramsden, D.A. and Lees-Miller, S.P. (2004). The DNA-dependent protein kinase: the director at the end. Immunol. Rev., 200, 132-141.

O'Neill, T., Dwyer, A.J., Ziv, Y., Chan, D.W., Lees-Miller, S.P., Abraham, R.H., Lai, J.H., Hill, D., Shiloh, Y., Cantley, L.C. and Rathbun, G.A. (2000). Utilization of oriented peptide libraries to identify substrate motifs selected by ATM. J. Biol. Chem., 275, 22719-22727.

Park, J., Hill, M.M., Hess, D., Brazil, D.P., Hofsteenge, J. and Hemmings, B.A. (2001). Identification of tyrosine phosphorylation sites on 3-phosphoinositide-dependent protein kinase- 1 and their role in regulating kinase activity. $J$. Biol. Chem., 276, 37459-37471.

Quevedo, C., Kaplan, D.R. and Derry, W.B. (2007). AKT-1 regulates DNA-damage-induced germline apoptosis in C. elegans. Curr. Biol., 17, 286-292.

Sarbassov, D.D., Guertin, D.A., Ali, S.M. and Sabatini, D.M. (2005). Phosphorylation and regulation of $A k t / P K B$ by the rictor-mTOR complex. Science, 307, 1098-1101.

Stephens, L., Anderson, K., Stokoe, D., Erdjument-Bromage, H., Painter, G.F., Holmes, A.B., Gaffney, P.R., Reese, C.B., McCormick, F., Tempst, P., Coadwell, J. and Hawkins, P.T. (1998). Protein kinase B kinases that mediate phosphatidylinositol 3,4,5-trisphosphate-dependent activation of protein kinase B. Science, 279, 710714.

Stokoe, D., Stephens, L.R., Copeland, T., Gaffney, P.R., Reese, C.B., Painter, G.F., Holmes, A.B., McCormick, F. and Hawkins, P.T. (1997). Dual role of phosphatidylinositol-3,4,5-trisphosphate in the activation of protein kinase B. Science, 277, 567-570.

Taccioli, G.E., Amatucci, A.G., Beamish, H.J., Gell, D., Xiang, X.H., Torres Arzayus, M.I., Priestley, A., Jackson, S.P., Marshak Rothstein, A., Jeggo, P.A. and Herrera, V.L. (1998). Targeted disruption of the catalytic subunit of the DNA-PK gene in mice confers severe combined immunodeficiency and radiosensitivity. Immunity, 9, 355-366.

Toker, A. and Newton, A.C. (2000). Akt/protein kinase B is regulated by autophosphorylation at the hypothetical PDK-2 site. J. Biol. Chem., 275, 8271-8274.

van Gent, D.C., Hoeijmakers, J.H. and Kanaar, R. (2001). Chromosomal stability and the DNA double-stranded break connection. Nat. Rev. Genet., 2, 196-206.

Viniegra, J.G., Martinez, N., Modirassari, P., Losa, J.H., Parada Cobo, C., Lobo, V.J., Luquero, C.I., Alvarez-Vallina, L., Ramon y Cajal, S., Rojas, J.M. and Sanchez-Prieto, R. (2005). Full activation of PKB/Akt in response to insulin or ionizing radiation is mediated through ATM. J. Biol. Chem., 280, 4029-4036.

Weterings, E. and Chen, D.J. (2007). DNA-dependent pro- 
tein kinase in nonhomologous end joining: a lock with multiple keys? J. Cell. Biol., 179, 183-186.

Weterings, E. and van Gent, D.C. (2004). The mechanism of non-homologous end-joining: a synopsis of synapsis. DNA Repair (Amst), 3, 1425-1435.
Yang, Z.Z., Tschopp, O., Baudry, A., Dummler, B., Hynx, D. and Hemmings, B.A. (2004). Physiological functions of protein kinase B/Akt. Biochem. Soc. Trans, 32, 350354. 